\title{
Salt Damage and Rising Damp Treatment in Building Structures
}

\author{
J. M. P. Q. Delgado, ${ }^{1}$ A. S. Guimarães, ${ }^{1}$ V. P. de Freitas, ${ }^{1}$ Iñigo Antepara, ${ }^{2}$ \\ Václav Kočí, ${ }^{2}$ and Robert Černý \\ ${ }^{1}$ CONSTRUCT-LFC, Faculty of Engineering, University of Porto, Rua Dr. Roberto Frias, s/n, 4200-465 Porto, Portugal \\ ${ }^{2}$ Department of Materials Engineering and Chemistry, Faculty of Civil Engineering, Czech Technical University in Prague, \\ Thákurova 7/2077, 16629 Prague 6, Czech Republic
}

Correspondence should be addressed to A. S. Guimarães; anasofia@fe.up.pt

Received 16 May 2016; Revised 30 September 2016; Accepted 5 October 2016

Academic Editor: Wei Zhou

Copyright (C) 2016 J. M. P. Q. Delgado et al. This is an open access article distributed under the Creative Commons Attribution License, which permits unrestricted use, distribution, and reproduction in any medium, provided the original work is properly cited.

Salt damage can affect the service life of numerous building structures, both historical and contemporary, in a significant way. In this review, various damage mechanisms to porous building materials induced by salt action are analyzed. The importance of pretreatment investigations is discussed as well; in combination with the knowledge of salt and moisture transport mechanisms they can give useful indications regarding treatment options. The methods of salt damage treatment are assessed then, including both passive techniques based on environmental control, reduction of water transport, or conversion to less soluble salts and active procedures resulting in the removal of salts from deterioration zones. It is concluded that cellulose can still be considered as the favorite material presently used in desalination poultices but hydrophilic mineral wool can serve as its prospective alternative in future applications. Another important cause of building pathologies is the rising damp and, in this phenomenon, it is particularly severe considering the presence of salts in water. The treatment of rising damp in historic building walls is a very complex procedure and at Laboratory of Building Physics (LFC-FEUP) a wall base hygroregulated ventilation system was developed and patented.

\section{Introduction}

Salt-induced damage represents a serious problem which a significant number of buildings must face. Besides other degradation mechanisms such as temperature changes, mechanical erosive actions of wind and water, or water phase changes, salt-induced damage may have both chemical and physical nature [1] that increases the effect of damage. It is very difficult to quantify its impacts because of lack of precise data. However, it is estimated that only the American and British transportation structures such as roads or bridges require approximately $\$ 450$ billion and $£ 616.5$ billion, respectively, to repair the damage caused by salts [2]. The situation in the building sector would probably be correlated, requiring hundreds of billions of dollars a year as the repair and maintenance costs.

Soluble salts can penetrate into buildings easily with moisture which can further transport them. Therefore, understanding of moisture transport processes in porous building materials is essential to prevent salt-induced damage. The effect of salts in the deterioration of historical buildings, which usually do not have horizontal waterproofing, has long been known and it is recognized worldwide, although it is not well understood, even when many distinct disciplines deal with the weathering caused by salts [3]. On the other hand, not only historical buildings but also modern constructions suffer from the attack of salt solutions. It has been found that different contaminants behave differently on bricks, stones, mortars, and also wood, which seems to react differently to the damaging action of salts and pollutants [4]. Therefore, it is important to understand the problem thoroughly regarding all the porous building materials and salt contaminants.

This review deals with the causes and mechanisms of salt-induced deterioration of buildings and describes and compares the desalination methods. The main objective of 
the review is to bring up the answers, partially or totally, to the most relevant questions formulated by Doehne [3]:

(i) Why are certain types of stone much more vulnerable than other types to salt damage?

(ii) Why are certain salts much more damaging than other salts?

(iii) Is damage caused mostly by relatively rare environmental events (rapid cooling) or cumulative everyday stresses (humidity cycling)?

(iv) What are the long-term effects of various conservation treatments, such as desalination or consolidation, on salt damage?

(v) How can desalination and preventive conservation efforts be enhanced?

Another important contribute of this review is to present a rising damp treatment technique, the HUMIVENT device [5-8], developed in the first years of this century by the Laboratory of Building Physics, Porto, Portugal, to treat and guarantee a good hygrothermal behaviour, of historical walls in contact with water and salts.

In this paper it is also intended to present a simplified methodology of sizing the wall base ventilation system for the treatment of rising damp.

\section{Moisture in Building Constructions}

2.1. Phases and Sources of Water. Salts can enter and move through porous bodies only when they are dissolved in water. It is therefore important to understand in detail the transfer of moisture in porous bodies. Water can enter a porous material in the liquid form and as a vapour and there are several mechanisms how this can happen: capillarity and infiltration in case of liquid water and condensation and absorption/adsorption in case of water vapour [9]. According to Straube [10], moisture in porous materials comes from several sources: it can come from the atmosphere (precipitation, condensed water, and adsorbed water vapour), it can come from activities and processes within the building, or it can be incorporated into the building materials from the ground and supply water (see Figure 1). Water can condense over the material surface but also inside the material pores. It is a complex process depending on the chemical-physical characteristics of both the atmosphere and the building material. Condensed water can be found in micropores at higher temperatures than theoretical dew point, even in relatively dry environments. The complete thermodynamic explanation was introduced by Camuffo [11] who described it as a reversible process for open pores and irreversible for internal pores. The necks connecting internal pores are filled with water at first, as they are the smallest pores. That means the process is blocked until the temperature changes.

There are four basic phases of water in porous building materials [12]: chemically bonded water, physically bonded water, capillary water, and nominally free water. Capillary action from rain or the ground is more effective than condensation. Penetration of rainwater into capillaries and

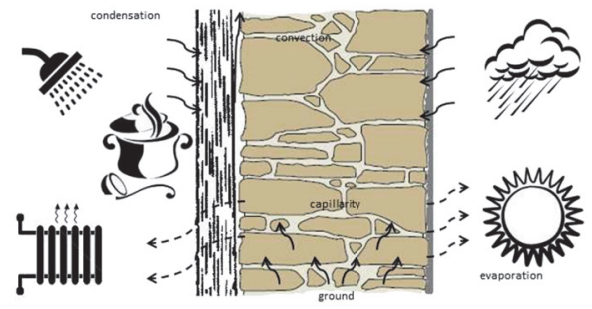

FIGURE 1: Moisture transport through masonry.

larger pores is possible only when the whole surface of the porous material is covered by a single or double layer of water molecules; otherwise water cannot penetrate when the surface is completely dry. Wind may also help this process [11]. Chemisorption, the chemical reaction with the pore surfaces, contributes to adsorption, as well as physical adsorption. Effects on adsorption of the external environment (relative humidity, air velocity, and temperature) are predominant over support type, salt solution properties, and the manner in which they interact. For desorption, the most significant factor is the material type (e.g., limestone, sandstone, or lime plaster).

Salts inside building materials also can absorb moisture. They can even become liquid (deliquescence), that is, absorb so much water vapour that they form a saturated solution. This process depends on the relative humidity. Regarding condensation in contact with a salt solution, it is a case of classical osmosis: water vapour in air condenses at lower vapour pressures as humid air near a salt solution reaches saturation earlier than in contact with pure water [9].

2.2. Moisture Transport. There are two moisture transport modes that occur in building materials: diffusion which is employed in case of water vapour and convection that takes place in case of liquid water. The driving force of water vapour is represented by the gradient of pressure [13]. Other driving forces may be present as well, that is, thermal or Knudsen diffusion. While thermal diffusion is usually neglected in civil engineering, Knudsen diffusion takes place in very narrow capillaries in which the mean free path of water molecules is larger than the pore dimensions. The driving forces for liquid water transport can be represented by capillary suction, surface diffusion [14], or thermodiffusion which is also known as the Soret effect. The capillary suction is usually the most important.

Size and shape of pores play significant role from the point of view of moisture transport. The ultracapillary pores, having the radius up to $10^{-9} \mathrm{~m}$, practically do not allow water movement as they have comparable dimensions to molecules of water. In the capillary pores, whose radius lies in the range $10^{-9}-10^{-3} \mathrm{~m}$, water and water vapour behave as in a system of capillary tubes and the movement is induced by the surface tension. Finally, the macropores and aerial pores larger than $10^{-3} \mathrm{~m}$ neglect the effect of capillary forces. In this case, the effect of gravity is dominant. 
2.3. Negative Effects of Moisture in Building Constructions. It is generally known that increased moisture of building materials is not desirable for several reasons. By absorbing moisture in form of water vapour or liquid water, building materials may increase their volume, more or less [9]. That may cause serious problems, typically, for materials containing swelling clays that can generate damaging stresses during wetting and drying $[15,16]$. Increased moisture content significantly contributes to decrease of mechanical properties of building materials [17], and it also affects the energy transport by changing the thermal conductivity and heat capacity of theirs $[18,19]$.

Furthermore, water can deteriorate building materials through solubilization, acting as a solvent for one or more components that can be washed out. However, wash-out and dissolution may only occur where great amount of water is collected, typically under windows [11].

Increased moisture content brings complications also in combination with temperature. When exposed to low temperatures, fully saturated materials may be vulnerable to freeze/thaw cycles [20]. However, presence of salts significantly decreases the liquid moisture freezing point and also the small pores may contribute to such a decrease [3]. On the other hand, combination of increased moisture and high temperature may be convenient for the development of biological degradation of building materials [20].

\section{Salts in Building Constructions}

3.1. Salt Sources. There are several possibilities how salts can be brought into constructions: from air pollution, sea spray [9], chemical reactions and decompositions [21], reconstructions and renovations [22], deicing agents, or rising damp [23].

Each salt has specific origin. Sulfates, sulfites, nitrates, and nitrites typically come from urban atmospheric deposition [24] but also from cement repairs [21]. Additionally, nitrates can be often found in agriculture buildings [25], they are also contained in bird excrements which can pollute the urban buildings. Chlorides represent a typical sea-site tracer [24] which can penetrate into buildings due to rising damp, salt spray, or flooding. Another reason can be found in utilization of sea water during mortars preparation [26] or by application of deicing salts for roads maintenance [21].

3.2. Physical and Chemical Effects of Salts. Deposited over the surface of the pores, salts can effectively decrease the pore sizes and therefore enhance suction [27]. They also affect the hygroscopic properties of materials, making them absorbing more moisture at the same external conditions [18]. Both of these phenomena lead to increase of the moisture content in building materials.

Salts are able to change the drying behaviour of building materials. It has been found that at low relative humidity the drying rate of a brick saturated with a salt solution is much lower than the drying rate of a brick saturated with water $[28,29]$. Also, a few paradoxes related to evaporation rates at different relative humidity were identified and explained $[28,30]$.
Several salts in building materials can be formed as a result of chemical actions of acids. For instance, carbon dioxide, a major source of acidity in natural waters, is the most responsible for rock weathering [31]. Another typical example is sulfur dioxide. Dissolved in water, it partly forms sulfurous acid and sulfur trioxide that forms acid as well. Both acids decompose lime and lime-mixed binders in coatings, resulting in the formation of gypsum [32]. In addition, nitric acid, originated from the oxidation of $\mathrm{NO}_{x}$ from combustion processes or $\mathrm{NH}_{3}$ contained in atmosphere, contributes to the decomposition of calcium carbonate and forms calcium nitrate on walls [25].

The hydrated calcium silicates and aluminates formed by the hydration of hydraulic binders can react with water and gypsum or sulfate salts and produce thaumasite and ettringite. Masonries might suffer another type of chemical degradation-alkali-amorphous silica reactions. It occurs between cement alkalis and aggregates containing reactive forms of mostly amorphous silica [33].

3.3. Salt Crystallization. Salt damage, in literature also known as salt attack, salt crystallization, or salt decay [3], can exhibit itself by efflorescence, contour scaling (flaking), granular disintegration (powdering or sanding), or alveolarization (honeycomb weathering). This damage is caused by salt phase transitions as a result of moisture transfer. Dissolved salt transported in water is deposited when the liquid is supersaturated which may easily happen in materials with high internal surface area [34]. This often happens when the moisture transport mechanism turns from liquid capillary transport to water vapour transport, because the salts cannot be transported in a gas phase [33]. During salt crystal growth, high stresses can arise even in large pores [35]. The crystallization pressure is higher in materials with small pores [36] as they can better maintain the supersaturation [37]. Other damage mechanisms may be employed as well, such as hydration pressure, different thermal expansion, or osmotic pressure but the crystallization pressure is the most important anyway [38]. It is affected by the characteristics of building material (pore structure), solution (viscosity, surface tension, vapour pressure), salt type, and environment (temperature, relative humidity). A more complete list of such factors was described by Doehne [3].

The damage caused by $\mathrm{NaCl}$ and other salts has a different mechanism: the salts produce an irreversible dilation during drying of the specimen and crystallization of the salt as a layer on the pore walls. No supersaturation appears to be reached by $\mathrm{NaCl}$ when crystallization occurs [39], among other things, due to solubility slightly dependent on temperature changes [40].

3.4. Salt Damage Treatments. Basically, there are two main principles of desalination of building constructions [30]. The first principle called passive techniques covers an environmental control, a reduction of transported moisture into a construction, or a conversion of contained salts to less soluble ones and hence less damaging. The second principle actively reduces the amount of contained salts by their transportation away from the zone of deterioration or preferably completely 
from the whole construction. However, before application of any salt damage treatment, the pretreatment investigation should be carried out thoroughly, revealing the nature of the salt damage.

3.4.1. Pretreatment Investigations. Before the main treatment, an evaluation of the salt damage is recommended, following these points of view.

(i) Evaluation of Salt Deterioration Problems. Presumably, none of the current models for modelling of salt and moisture transport processes in porous media is fully applicable to the heterogeneous aged materials found in both historical and contemporary buildings. Simulations cannot substitute rigorous site-based observations and study [30].

(ii) Evaluation of the Historical and Cultural Value. Information about the original aspect, the significance (i.e., as evidence of a certain style, taste, or building method), the aesthetic/historic/cultural role of the object within its context (e.g., urban), all original construction and restoration (substitution of materials, addition of parts) phases and their historical and technical relevance, and/or the function(s)/use should be described.

(iii) Additional Investigations. These include a survey of the liquid moisture sources, the environmental conditions, and sampling for analysis [41].

If the salt penetration is found, based on above described evaluation, and desalination treatments must be applied once or repeatedly, the additional information should be gathered based on the in situ sampling. Their evaluation should primarily give the information about the composition of building materials and their pore structure characteristics, moisture quantity and distribution, and salts type, quantity, and distribution [41].

3.4.2. Passive Techniques. The essence of passive techniques is based on prevention of the causes of salt damage, increased moisture in particular.

Condensed water inside the walls is one of the sources of damp. Back in the 70s of the last century, the initial efforts to energy savings led to implementation of thermal insulations that were waterproofed mostly. The addition of thermally insulation layer to the interior side of an uninsulated wall decreases the temperature of the masonry during the heating season in cold climates. This can increase the risk of condensation inside the wall [42], mainly affecting outside corners, windows, slatted roller blind housings, ceilings, and the masonry wall base on unheated cellars. Even if these weak points can be easily eliminated using constructional measures, increased heating together with ventilation was recommended instead. Thus, the final energy consumption decreased only slightly despite the application of thermal insulation and water vapour evaporation remained hindered. Nowadays, vapour retarders have been devised to control moisture flow by vapour diffusion into the wall structure [43].
The second source of moisture is represented by rising damp that building materials absorb from the ground together with ions. Due to capillary rise and evaporation, less soluble salts will therefore reach saturation earlier, resulting in a fractionation of the crystals. However, it is very difficult to predict the precipitation sequence [31]. Due to this fractionation following zones can be distinguished in the masonry absorbing ground moisture, although it is not possible to allocate the specific zone for each of the salt solutions in advance. Less soluble salts precipitate in the lowest zone, followed by the zone of the greatest damage. The upper zone remains still wet because of rising damp instigated by the most soluble and deliquescent salts. The highest zone in the masonry is dry and unaffected by salts [9].

Franzoni [44] proposed several preventive or remedial strategies against rising damp, grouped according to their background principle:

(i) reduction of the water flux in ingress;

(ii) reduction of the overall sorptivity of the wall by reducing the porosity of materials, by decreasing the wettability of materials, or by reducing the wall crosssection (wall cutting is also included);

(iii) enhancement of the water evaporation rate from the masonry;

(iv) exploitation of electrokinetic effects.

The most effective method reducing the water flux is prevention through the physical separation of building materials from the ground moisture and salts by the use of a traditional damp-proof course. An impermeable barrier such as plastic, glazed brick, or bitumen is typically used [45]. However, using such protection measures in historical masonry is mostly not feasible.

The second strategy is based on assumption that reducing of water transport in a porous media implies that the salt transport will be reduced as well. In the past few decades, an increased use of injection of chemical damp-proof courses in masonry walls was detected due to high cost of several other treatments, such as replacement of poulticing [46]. Among the most frequently used chemicals, liquid water based silane/siloxane products were showed to spread homogeneously and reduce water uptake the most efficiently [47].

Within the frame of the third group of strategies, the HUMIVENT technique has been proposed to reduce the level of rising damp [48]. It consists of ventilating the base of walls using a natural ventilation process or by installing a hygroregulated mechanical ventilation system.

Electroosmotic method, belonging to the last group of strategies, has been used for many years to reduce the amount of moisture ascending in the building walls [49]. It has been showed, however, that the efficiency of the method is questionable as the ionic concentration must be low $[50,51]$.

Besides condensation and rising damp, also the atmosphere is a significant source of moisture. Therefore, the type of finish of the building envelope defines its ability to absorb moisture [52], while its roughness provides a greater specific surface to react with the environment [53]. 
Also chemicals may present the appropriate strategy to avoid intake of atmospheric moisture. The ammonium oxalate treatment should be preferred to the polysiloxane treatment in the presence of soluble salts, even after desalination procedures, which might not remove them completely. In addition, the neoformed calcium oxalate seemed to effectively protect the stone, improving its resistance against salt crystallization without occluding the pores and limiting the superficial erosion caused by atmospheric agents [54]. Hybrid coatings (i.e., polysiloxane plus Ti solutions) seem to be more effective in reducing salts formation with respect to the pure resin. However, a cleaning pretreatment is mandatory before the application of a new protective film [55]. Titania and silica nanocomposite materials efficiently penetrate into the pores of stones [56].

Paintings represent another option to protect the walls against atmospheric moisture. However, they do not work on salt-laden materials because paints tend to increase the presence of moisture and salt deposition on or close to the surface of walls. Additionally, the salt accumulation behaviour and related features of different plasters/renders may be differently affected by paint layers [57]. As a result, paints used in a saline environment begin to deteriorate after two years [58].

Also repair mortars can be used for waterproofing of masonry [59] when they contain siloxane coating that repels water and allows permeability of water vapour. In this case, moisture does not accumulate in between the coating and the substrate. On the other hand, severe damage can occur if rendered zones are combined with uncovered elements on facades. Moisture and salt transport is then redirected into these zones where evaporation is less hampered [60].

3.4.3. Active Desalination Techniques. Active desalination techniques can be very effective for salt damage reduction, especially in cases where the damage is induced by cyclic dissolution and crystallization of salts as a response to relative humidity changes. Furthermore, no additional ingress of liquid water should be involved. According to Young and Ellsmore [61], early signs of breaking down of a well-made and well-cured sacrificial mortars or renders may lead to the decision to proceed to desalination treatments.

There are several desalination methods available. Some of them are even at the experimental stage; therefore only the most frequently used ones are included in the presented review. These methods can be divided into the following categories:

(i) dry-mechanical methods,

(ii) diffusive methods (baths),

(iii) methods based on diffusion and evaporation (poultices),

(iv) convective methods (by hydrostatic pressure or suction),

(v) other methods (microwaves or biological denitrification).
There are also some methods which can be classified as outdated; therefore they should not be considered anymore. Hard cement renders, damp-proof mortar additives, Knapen tubes, or passive electroosmosis can be named as the methods belonging to this group.

(1) Dry-Mechanical Methods. The principle of dry-mechanical methods consists in removal of salt efflorescence from the surface usually by its brushing. Besides the primary removal of salts from the masonry, it can secondarily affect the thermodynamic behaviour of salts in relation to environmental conditions. Cleaner wall surface will also increase the evaporation rate [62] which may improve the drying behaviour of the object [30].

(2) Diffusive Methods. Prolonged immersion and repeated or intermittent washing are the most frequently mentioned methods belonging to the diffusive category that is also called bath methods. The principles of these methods are very similar. At first, diffusion drives the extraction of salts, following a linear dependence on time according to Fick's law. Then, controlled by other factors such as concentration gradient, solubility, or dissolution kinetics, the process slows down until the limiting value is reached. Moreover, the type of salt and the way of its distribution in the sample can also affect the whole extraction process. A repeated washing is usually more efficient except for sulfate salts [63] and generally, the diffusive methods are the most efficient when the salt-laden objects can be submerged in distilled water.

The bath methods are not used so often. The condition of the salt-laden objects to be submerged in distilled water is too restrictive. Therefore, they are applicable only for relatively small and movable objects that are not sensitive to water [41].

(3) Electrokinetic Methods. Compared to diffusion methods, salt transport and thus removal by electromigration become dominant over diffusion even at minimum level of applied voltage [63]. Electromigration then continues until very low and harmless salt contents are reached [64], which is the main principle of this method.

On the other hand, electrokinetic method may have several disadvantages such as possible oxidation of ferrous materials and electrodes, hydrolysis, and extreme $\mathrm{pH}$ values [60]. The last disadvantage was eliminated by Rörig-Dalgaard [65], who introduced a special poultice that works as a buffer component and is able to efficiently neutralize the acid from electrolysis at the anode [65]. It is a cathode unit consisting of a three-layered poultice which neutralizes the electrochemical induced hydroxide with a buffering agent. The process is followed by precipitation of the buffering agent, citric acid, to calcium citrate inside the cathode poultice ensuring stable $\mathrm{pH}$ in the substrate. In addition, the precipitation of calcium citrate within the cathode poultice prevents new ions to enter the substrate during the desalination [66].

Based on previous observations [60], the electrokinetic method seems to work ion-selectively. The best results have been achieved related to alkaline and chloride ions while the removal rate depends on the associated cation [46]. On 
the other hand, only the minor part of magnesium part can be extracted. The removal rate of sulfates is also considerably slower than chlorides or nitrates, which results in gypsum precipitation inside the porous body of the materials [66].

(4) Plasters. There are several types of plasters according to their mechanisms of salt and moisture transport [67], but not all of them are suitable for desalination [68].

(i) Salt transporting systems allow the solution to migrate through the plaster and crystallize on the surface.

(ii) Salt accumulating systems are able to absorb the salt solution from the underlying substrate and let it crystallize (accumulate) within the mortar.

(iii) Salt blocking systems allow transport of water vapour only, while the salt solution is blocked inside the substrate.

(iv) Moisture sealing systems ensure that both liquid water and water vapour are not allowed to cross the interface between the substrate and the mortar.

The effect of salt transportation systems is based on their pore space characteristics having the optimal structure that allows absorption of salt solution without its accumulation [69]. It means if the pores of the plaster are smaller than those of the salt-polluted masonry material, all soluble salts are removed from the substrate. If the substrate has a considerable amount of pores that are smaller than those of the plaster, some salt might crystallize in the plaster but a significant amount of the salt remains within the substrate itself [69]. The accumulating systems gain their specific properties due to the presence of additives, such as water repellents [69]. Generally, the plasters with the ability to transport the salt solution from the masonry are preferred to salt blocking systems [70].

When the plasters are able to incorporate salts in their pore space but are not resistant against their crystallization, they can be used as the so-called sacrificial layers [60]. This method is frequently used to minimize the salt deterioration of masonry although it means that used plasters have to be replaced periodically. As a typical example, lime plasters can be named, which do not reduce the evaporation and, in comparison with cement plasters, can be easily removed without remnants.

(5) Poultices. Aqueous extraction using poultices is the most popular and the most frequently used desalination method [71] because of its simplicity and efficiency. On the other hand, only the subsurface zone of the treated masonry is affected [72]. The desalination process has two main phases [73]. In the wetting phase, water is transported from the poultice into the wall where it starts to dissolve the salts. Then, in the extraction phase, the dissolved salt ions travel in the form of an aqueous saline solution from the wall back into the poultice. The salt migration is generated either by the existence of a concentration gradient between the object and the poultice, in which case the salt ions diffuse through the solution, or by capillary water flow from the object to the poultice (generally due to drying) in which the ions are advected within the solution [74].

In the case of diffusion-based desalination, the object is brought into contact with aqueous salt solution, whose concentration is close to zero. Then, based on the Brownian motion of the dissolved salt molecules, the equilibrium concentration is reached in the poultice as well as in the treated object. This process can be described by Fick's second law adapted to the pore structure, that is, incorporating the porosity and tortuosity of the material. In general, diffusionbased poulticing works independently on the pore size, but the poultices have to be renewed frequently and a good hydraulic contact between poultice and object has to be maintained. As it is a slow method, a sufficient time period is required. Unfortunately, such a long contact with water may have several disadvantages as the masonry and adjacent structures can suffer from physical and/or chemical effects, and microorganisms may also grow. On the other hand, the very high efficiency of this method is a reward and materials with very low pores $(<0.1 \mu \mathrm{m})$ can be treated only in this way [41].

As advection is generally more rapid than diffusion, advection-based desalination methods are much faster than the diffusion-based. In this case, the desalination process is governed by the moisture flow from the object to the poultice. This is ensured by the significant quantity of pores of poultice that are smaller than those of the treated object. Also a good hydraulic contact between the poultice and the object is required. Compared to diffusion methods, less moisture is brought into the object and also smaller number of repetitions is required [75]. Additionally, the accumulation of salt in the poultice can effectively decrease the pore sizes and improve the salt extraction process [76]. On the other hand, during the extraction the increasing accumulation of salt will reduce the rate of moisture loss by evaporation and may promote the rate of back diffusion from the poultice into the substrate. Therefore, the poultices have to be renewed too [73].

As it was mentioned before, the application time of a poultice is strongly dependent on the dominant transport mechanism. In the case of diffusion-controlled "wet poultices" it is important to keep the salt content in the poultice as low as possible in order to maintain the concentration gradient. Because diffusion is a relatively slow process, one has to reapply the poultice often for a very long time, that is, month or weeks rather than days. By contrast, in the case of advection controlled "drying poultices" the initial drying period where salts are mobilized by liquid transport is important. Consequently, one should apply the poultice for as long as this transport mechanism is dominant which is generally in the order of days. Indeed, overly long application times of drying poultices increase the risk that diffusion becomes dominant to advection which may lead to back diffusion of salt from the poultice into the object [30], as water tends to flow from a region with a less concentrated solution to a region with a more concentrated solution [27]. 


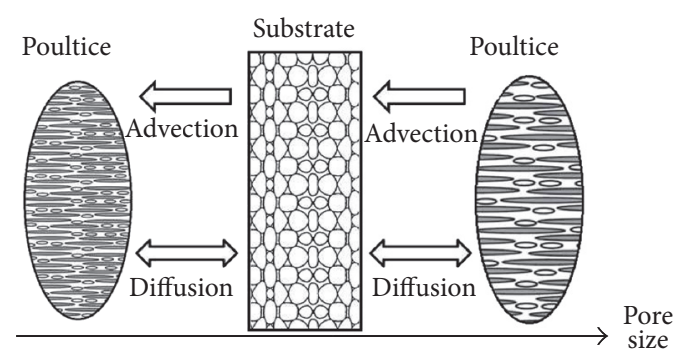

FIGURE 2: Behaviour of poultices as a function of their pore size compared to the pore size of a substrate.

The competition between two mechanisms of transport, advection and diffusion, can be characterized by the Peclet number, $\mathrm{Pe}$, as [27]

$$
\mathrm{Pe}=\frac{|U| L}{D_{\text {eff }}},
$$

where $U\left[\mathrm{~m} \mathrm{~s}^{-1}\right]$ is the moisture velocity, $D_{\text {eff }}\left[\mathrm{m}^{2} \mathrm{~s}^{-1}\right]$ is the effective diffusion coefficient of the salt in the porous material, and $L[\mathrm{~m}]$ is the length scale of interest. For Pe $\ll 1$ diffusion dominates and ion transport proceeds according to the concentration gradient. If $\mathrm{Pe} \gg 1$, then advection dominates and ion transport takes place due to capillary water flow. It is important to keep the drying rate sufficiently high as long as possible to maintain Pe above 1 in order to extract a maximal amount of salt from a treated object. In practice this means that the air at the drying surface has to be refreshed at a sufficient speed [58].

Based on the above mentioned, it is preferable to use advection-based poultices [75]. For this purpose, the poultice has to be adapted to the pore-size distribution of a substrate in order to create effective salt extraction by poultices [41]. The scheme of behaviour of poultices as a function of their pore size is depicted in Figure 2.

According to the general consensus [41,77], the following aspects should be considered before desalination treatment using poultices:

(i) Water content of poultice to supply appropriate amount of water during the wetting phase.

(ii) Grain packing, size, and arrangement of grains as they influence the connectivity between pore classes.

(iii) Pore-size distributions of the substrate and of the poultice.

(iv) Shape of the pores as suction properties of sheet-like throats seem less effective than tube-like throats.

(v) Consistency and thus the resistance of poultice to deformation.

(vi) Workability as it has a direct influence on the adhesion of the poultice to the substrate.

(vii) Drying shrinkage as it influences the adhesion of the poultice to the substrate as well.

(viii) Adhesion as desalination effectiveness can be significantly reduced if the poultice detaches too early during the drying phase.
The most frequently used poultices are those being the easiest to prepare and apply and having the good adhesion to the substrate [71]. There are three major components that can be found in any type of poultice: an inert material to reduce the shrinkage (e.g., sand), moisture reservoir, and a mineral as active salt extracting component and also moisture retainer. Varying the type of components and their ratios, the poresize distribution of a poultice can be controlled [41]. If the poultice is intended to have the dual function of both wetting and desalination, it must have a wide pore-size distribution incorporating large pores acting as reservoirs for wetting as well as small pores ensuring the advection from the substrate to the poultice. Moreover, potential changes in the porosity and pore-size distribution of the poultice material during drying need to be also taken into account [73].

Cellulose poultices represent the most frequently used material in desalination processes [71], no matter if the cellulose comes from cotton wool, blotting paper, or newspaper or is used in the form of powdered cellulose fibers [78].

The reason of their frequent application lies in their advantages. Their softness makes them possible to be applied on rough or fragile surfaces. Additionally, they are easy to be handled and can be removed without leftovers [60]. Neutral $\mathrm{pH}$, high water absorption, plasticity, and adhesion may be listed as other advantages [78]. Thanks to presence of cellulose fibers, excessive water content does not affect their consistency as in case of other materials [77]. According to findings presented by Auras [60], the poultices may be used repeatedly as the salts can be washed out.

On the other hand, cellulose poultices have also several disadvantages, such as an occasional development of molds, a tendency to redistribute surface salts deeper into the body, or poor water retention when applied on vertical surfaces [78]; this can lead to poor adhesion. Sometimes salt efflorescence or a large material loss has been observed. Cellulose poultices also require longer preparation time than clays.

Another large group of poultice materials used in desalination is formed by clay minerals and mixtures of clay minerals and sand [71]. Frequently used clay minerals are montmorillonite, kaolinite, hydrotalcite, allophane, bentonite, kaolinite, or sepiolite [60].

Bentonite-rich poultices are efficient when wet, thanks to osmotic pressure. Kaolinite-rich poultices require more time to reach the same salt extraction efficiency, but they perform well when dry due to capillary suction [79]. However, they may leave white residues, which might be a problem in the case of dark colored and/or particularly sensitive surfaces.

The best results from the point of view of salt extraction were achieved when poultices containing the mixes of several components were used [80]. For example, the cellulosekaolin-sand poultice exhibits a good performance as cellulose works as the water reservoir, kaolin extracts the water solution from the substrate by capillary suction, and sand is used to reduce the shrinkage.

Despite the extensive research and progress that has been reached in the field of desalination of building constructions using poultices, current methods are still not efficient enough in a certain way (mold growth, reverse osmosis, or extreme $\mathrm{pH}$ values). Therefore, a development of new conservation 
treatments is required that can preferably be applied for both preventing salt damage development and promoting effective desalination. Hydrophilic mineral wool is often mentioned in that respect as an alternative to commonly used cellulose [46]. Contrary to cellulose, mineral wool is an inorganic material that does not support the mold growth affecting negatively the maintenance of the poultice. Moreover, it does not shrink during drying which ensures its adhesion to the treated surface. However, even if mineral wool poultices were already involved in desalination process of a castle in France [81], their further investigation is still needed. Several researches were therefore performed, aiming at determination of heat and moisture storage and transport properties using different techniques $[82,83]$. The water and chloride absorption coefficients as well as corresponding moisture diffusivities were found very high [84] which is beneficial for the application as a poultice material. However, it was found that after repeated wetting-drying the water absorption coefficient dropped which was explained by the partial leaking of the hydrophilic substance. This fact significantly reduces the repeated application of mineral wool poultices, even if the contained salt may have positive effect on water absorption and thus can partially compensate the absence of hydrophilic substance. Therefore, future research of mineral wool poultices aims at optimization and experimental verification of moisture and salt transport and storage properties and subsequent semiscale testing on salt-laden masonry.

\section{Rising Damp Treatment in Historical Buildings}

4.1. The Wall Base Ventilation System. Water associated with salts is one of the main degradation factors of historic building. There are two main sources of buildings water supply: the phreatic waters and surface waters. The phreatic waters come from the ground and rising damp is a consequence. In this sense an innovative technique was developed, "wall base ventilation system" which consists of circulating air in the walls base with a relative humidity away from the saturation and with steam pressure conditions favorable to the walls drying. The wall base ventilation system increases evaporation, which reduces the level achieved by the damp front.

This technique should be used when the system's bottom comes above the water phreatic level. A ventilation system with channels associated with a hygroregulated mechanical ventilation device, which makes the system operate in accordance with predefined sizing criterions, can be designed (see Figure 3).

In the Laboratory of Building Physic, LFC, of the Faculty of Engineering, University of Porto, FEUP, several works have been developed that greatly contributed to the system's sizing. For over 15 years the phenomena of rising damp in building walls have been studied $[85,86]$.

At the beginning of the last decade merges the idea of ventilating the wall base as a rising damp treatment technique $[87,88]$. The ventilation, initially thought as natural, quickly came to be conceived as a mechanical controlled process [88].
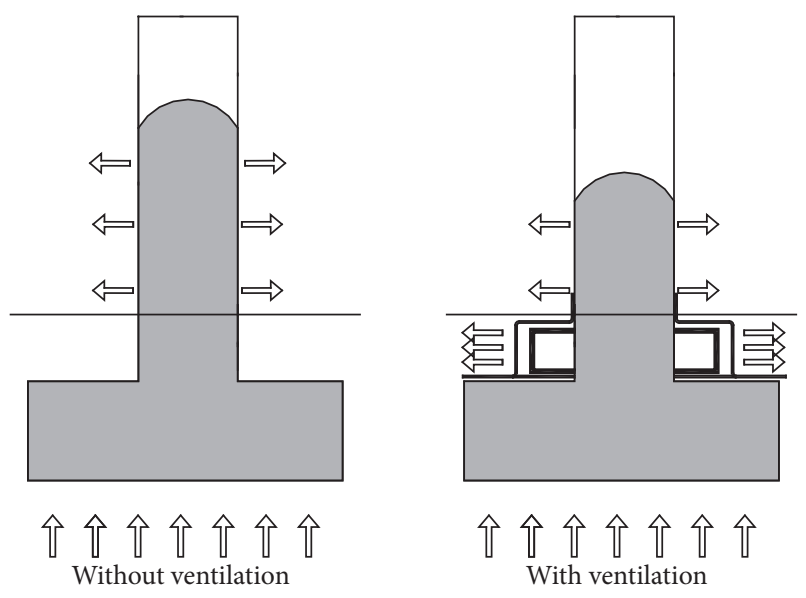

Figure 3: Wall base ventilation system principle.

In this framework several laboratory studies and numerical simulations in walls, with and without the system, in order to validate this new technology, were developed [87-90].

In 2002 some tests campaign began in a church, where these systems were implemented for the first time [91] followed by the use of those systems in other buildings. It was in 2005 that new experimental campaigns in laboratory environment were done, with the aim to characterize the system, in particular, their geometry [92]. Other parameters were evaluated as the speed of air circulation and air admission characteristics [91]. In 2007 it was found that although the system reduce the level reached by the wet front, condensations inside the system can occur, which is undesirable. It was considered necessary to use a hygroregulated system able to control the occurrence of such condensations based on predefined criteria [91, 93]. In 2008 began the development of a sizing system model $[8,94-103]$. Sensitivity studies were simultaneously evaluated [8].

In field implemented systems were adapted in 2009 with new operating criteria, studied, and optimized, with the purpose of controlling condensation occurrences and crystallization formation and/or salts dissolutions, starting a new campaign. A survey was conducted to assess the originality of the proposed system but the systems found, apparently similar, just actively drain the water from the walls base or remove vapours and gases from buildings [104-106]. This analysis allowed to conclude that this is an innovative technology and initiated a patent application of the University of Porto, UPIN, titled "Hygro-Adjustable Wall Base Ventilation System" [107] shown in Figure 4.

4.2. Salts Solutions versus Wall Base Ventilation System. The model describes a mass balance where, in steady state, the capillary water absorption rate equals the rate of evaporation. If the water that runs through the structure contains appreciable quantities of dissolved salts, which is very common, then there is an additional component for the mass balance and there is an accumulation of salts in the wet region. This leads to a gradual increase in the concentration of salt dissolved in the water stored that may lead to deposition of salt within the 


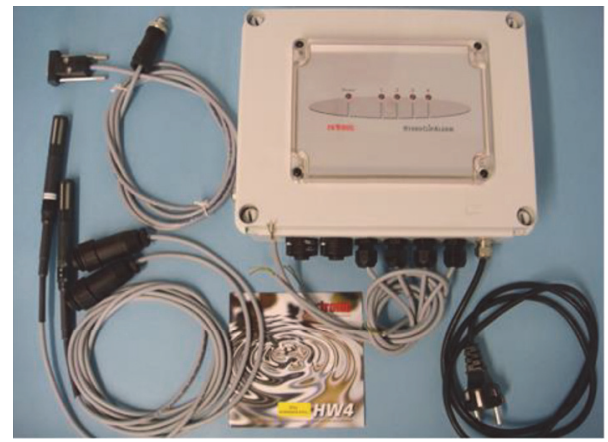

Figure 4: Patent system.

mesh or solid surface. These processes are not incorporated into the model, although some of their effects can be added. The absorption may be adjusted, if necessary, by a small change in the value of the sorptivity. More importantly, in the presence of salts the evaporation rate is reduced by a factor $\left(p_{\text {sal }}\right) /\left(p_{p}-p_{a}\right)$, where $p_{\text {sal }}$ is the vapour pressure of the solution of salt on the surface, $p_{p}$ is the vapour pressure of pure water, and $p_{a}$ is the vapour pressure of water in the environment [108].

\section{Conclusions}

A thorough review of scientific literature dealing with salts in the deterioration process of porous building materials was presented and principal factors responsible for the degradation processes were analyzed. The main results can be summarized as follows:

(1) When treating the damage caused by salts in building materials, avoiding the source of damp is found often enough to lead to the solution of the problem. However, if the salts are already contained in the masonry, various desalination methods have to be applied. The historical masonry can be named as a typical example, as a physical separation of building materials from the ground moisture is mostly not feasible or completely missing.

(2) The dry-mechanical removal of surface efflorescence is used only marginally. Similarly, the bath methods are not used frequently because of their substantial limitations. The electrokinetic methods have certain disadvantages as they require high humidity and work ion-selectively. The purpose-designed plasters for desalination are being used more often, especially those containing natural hydraulic lime, which are preferred to cementitious materials because they can be removed easily from masonry without remnants. They can be also used as sacrificial layers.

(3) Among all the desalination methods, aqueous extraction by poulticing is the most popular one. There are several poulticing materials that can be used; clay minerals and cellulose belong to the most favorite and most frequently ones. However, despite extensive investigations some disadvantages are still preserved, such as mold growth, shrinkage, or reverse osmosis. Therefore, new poulticing materials are still being developed. Based on the results presented so far it can be concluded that even if cellulose can be considered as the favorite material presently used in desalination poultices, hydrophilic mineral wool can serve as its prospective alternative in future applications.

The treatment of rising damp is a problem difficult to solve and of the utmost importance in monuments and historical buildings. According to the performed study the following conclusions can be reached:

(1) The treatment of rising damp in monuments and historical buildings is a problem scarcely difficult to solve.

(2) Despite the existence of many treatment solutions and techniques we consider the use of air with controlled relative humidity the most suitable treatment principle.

(3) An hygroregulated wall base ventilation device is essential to control condensation occurrences inside the system.

(4) The model should consider not only pure water but also salt solutions as this is the real and most important problem.

\section{Competing Interests}

The authors declare that they have no competing interests.

\section{Acknowledgments}

Iñigo Antepara, Václav Kočí, and Robert Černý would like to thank Czech Science Foundation, under Project no. P105/12/G059. J. M. P. Q. Delgado would like to thank FCT for financial support through the Grant SFRH/BPD/109310/ 2015.

\section{References}

[1] J. Skalny, J. Marchand, and I. Odler, Sulfate Attack on Concrete, Spon Press, New York, NY, USA, 2002.

[2] J. Broomfield, Corrosion of Steel in Concrete: Understanding, Investigation and Repair, Taylor \& Francis, New York, NY, USA, 2nd edition, 2007.

[3] E. Doehne, "Salt weathering: a selective review," Geological Society Special Publication, vol. 205, no. 1, pp. 51-64, 2002.

[4] E. Morabito, E. Zendri, R. Piazza et al., "Deposition in St. Mark's Basilica of Venice," Environmental Science and Pollution Research, vol. 20, no. 4, pp. 2579-2592, 2013.

[5] V. P. de Freitas, A. S. Guimarães, and J. M. P. Q. Delgado, "The "Humivent" device for rising damp treatment," Recent Patents on Engineering, vol. 5, no. 3, pp. 233-240, 2011.

[6] J. M. P. Q. Delgado, A. S. Guimarães, and V. P. de Freitas, "Analysis and monitoring of the drying process of a hygro-regulated wall base ventilation system implemented in a historical church 
to control rising damp," Drying Technology, vol. 31, no. 4, pp. 385-392, 2013.

[7] A. S. Guimarães, J. M. P. Q. Delgado, and V. P. de Freitas, "Rising damp in walls: evaluation of the level achieved by the damp front," Journal of Building Physics, vol. 37, no. 1, pp. 6-27, 2013.

[8] A. S. Guimarães, J. M. P. Q. Delgado, and V. P. de Freitas, "Mathematical analysis of the evaporative process of a new technological treatment of rising damp in historic buildings," Building and Environment, vol. 45, no. 11, pp. 2414-2420, 2010.

[9] A. E. Charola, "Salts in the deterioration of porous materials: an overview," Journal of the American Institute for Conservation, vol. 39, no. 3, pp. 327-343, 2013.

[10] J. F. Straube, "Moisture in buildings," ASHRAE Journal, vol. 44, no. 1, pp. 15-19, 2002.

[11] D. Camuffo, "Physical weathering of stones," Science of the Total Environment, vol. 167, no. 1-3, pp. 1-14, 1995.

[12] Neville, Properties of Concrete, Pearson, New York, NY, USA, 5th edition, 2011.

[13] W. Stewart Jr., "Effect of air pressure differential on vapor flow through sampler building walls," ASHRAE Transactions, vol. 104, p. $17,1998$.

[14] I. Medved' and R. Černý, "Surface diffusion in porous media: a critical review," Microporous and Mesoporous Materials, vol. 142, no. 2-3, pp. 405-422, 2011.

[15] T. Wangler and G. W. Scherer, "Clay swelling mechanism in clay-bearing sandstones," Environmental Geology, vol. 56, no. 34, pp. 529-534, 2008.

[16] T. Wangler and G. W. Scherer, "Clay swelling inhibition mechanism of $\alpha, \omega$-diaminoalkanes in Portland Brownstone," Journal of Materials Research, vol. 24, no. 5, pp. 1646-1652, 2009.

[17] H. Kus and K. Nygren, "Microenvironmental characterization of rendered autoclaved aerated concrete," Building Research and Information, vol. 30, no. 1, pp. 25-34, 2002.

[18] M. Koniorczyk and M. Wojciechowski, "Influence of salt on desorption isotherm and hygral state of cement mortarmodelling using neural networks," Construction and Building Materials, vol. 23, no. 9, pp. 2988-2996, 2009.

[19] C. Rode and C. Rudbeck, "Latent heat flow in lightweight roofs and its influence on the thermal performance of buildings/Discussion," ASHRAE Transactions, vol. 104, p. 930, 1998.

[20] V. Kočí, J. Maděra, J. Fořt et al., "Service life assessment of historical building envelopes constructed using different types of sandstone: a computational analysis based on experimental input data," The Scientific World Journal, vol. 2014, Article ID 802509, 12 pages, 2014.

[21] T. Warscheid and J. Braams, "Biodeterioration of stone: a review," International Biodeterioration \& Biodegradation, vol. 46, no. 4, pp. 343-368, 2000.

[22] J. E. Lindqvist, "Rilem TC 203-RHM: repair mortars for historic masonry. Testing of hardened mortars, a process of questioning and interpreting," Materials and Structures, vol. 42, no. 7, pp. 853-865, 2009.

[23] E. Doehne and C. Price, Stone Conservation: An Overview of Current Research, The Getty Conservation Institute, Los Angeles, Calif, USA, 2nd edition, 2010.

[24] C. Hall and W. Hoff, "Liquid movements," Materials World, vol. 15, no. 1, pp. 24-26, 2007.

[25] G. Zappia, C. Sabbioni, C. Riontino, G. Gobbi, and O. Favoni, "Exposure tests of building materials in urban atmosphere," Science of the Total Environment, vol. 224, no. 1-3, pp. 235-244, 1998.
[26] L. Skytte, K. L. Rasmusen, M. Ryhl-Svendsen, B. Svensmark, and P. Brimblecombe, "Ammonia chemistry within Danish churches," Science of the Total Environment, vol. 417-418, pp. 1320, 2012.

[27] B. Lubelli, R. P. J. Van Hees, and H. J. P. Brocken, "Experimental research on hygroscopic behaviour of porous specimens contaminated with salts," Construction and Building Materials, vol. 18, no. 5, pp. 339-348, 2004.

[28] V. Voronina, L. Pel, and K. Kopinga, "Effect of osmotic pressure on salt extraction by a poultice," Construction and Building Materials, vol. 53, pp. 432-438, 2014.

[29] S. Gupta, H. P. Huinink, M. Prat, L. Pel, and K. Kopinga, "Paradoxical drying of a fired-clay brick due to salt crystallization," Chemical Engineering Science, vol. 109, pp. 204-211, 2014.

[30] V. Brito and T. Diaz Gonçalves, "Drying kinetics of porous stones in the presence of $\mathrm{NaCl}$ and $\mathrm{NaNO}_{3}$ : experimental assessment of the factors affecting liquid and vapour transport," Transport in Porous Media, vol. 100, no. 2, pp. 193-210, 2013.

[31] A. M. Sawdy-Heritage, L. Pel, and A. Heritage, "A review of salt transport in porous media: assessment methods and salt reduction treatments," in Proceedings of the Salt Weathering on Buildings and Stone Sculptures (SWBSS '08), pp. 1-27, The National Museum, Copenhagen, Denmark, October 2008.

[32] "Salts and crusts", in The Effects of Air Pollution on the Built Environment, M. Stieger, Ed., pp. 133-181, World Scientific, River Edge, NJ, USA, 2003.

[33] P. Rovnaníková, "Environmental pollution effects on other building materials," in Environmental Deterioration of Materials, A. Moncmanová, Ed., pp. 217-248, WIT Press, Southampton, UK, 2007.

[34] M. Collepardi, "Degradation and restoration of masonry walls of historical buildings," Materials and Structures, vol. 23, no. 2, pp. 81-102, 1990.

[35] A. Putnis, M. Prieto, and L. Fernandez-Diaz, "Fluid supersaturation and crystallization in porous media," Geological Magazine, vol. 132, no. 1, pp. 1-13, 1995.

[36] G. W. Scherer, "Stress from crystallization of salt," Cement and Concrete Research, vol. 34, no. 9, pp. 1613-1624, 2004.

[37] D. Benavente, M. A. García del Cura, J. García-Guinea, S. Sánchez-Moral, and S. Ordóñez, "Role of pore structure in salt crystallisation in unsaturated porous stone," Journal of Crystal Growth, vol. 260, no. 3-4, pp. 532-544, 2004.

[38] G. W. Scherer, "Crystallization in pores," Cement and Concrete Research, vol. 29, no. 8, pp. 1347-1358, 1999.

[39] L. Pel, H. Huinink, and K. Kopinga, "Ion transport and crystallization in inorganic building materials as studied by nuclear magnetic resonance," Applied Physics Letters, vol. 81, no. 15, pp. 2893-2895, 2002.

[40] B. Lubelli, R. P. J. van Hees, H. P. Huinink, and C. J. W. P. Groot, "Irreversible dilation of $\mathrm{NaCl}$ contaminated lime-cement mortar due to crystallization cycles," Cement and Concrete Research, vol. 36, no. 4, pp. 678-687, 2006.

[41] R. van Hees, B. Lubelli, S. Naldini et al., Guideline for Desalination of Porous Substrates, 2013.

[42] J. Straube and C. Schumacher, "Interior insulation retrofits of load-bearing masonry walls in cold climates," Journal of Green Building, vol. 2, no. 2, pp. 42-50, 2007.

[43] J. Toman, A. Vimmrová, and R. Černý, "Long-term on-site assessment of hygrothermal performance of interior thermal insulation system without water vapour barrier," Energy and Buildings, vol. 41, no. 1, pp. 51-55, 2009. 
[44] E. Franzoni, "Rising damp removal from historical masonries: a still open challenge," Construction and Building Materials, vol. 54, pp. 123-136, 2014.

[45] N. Harmati, Ž. Jakšić, M. Trivunić, and V. Milovanovi, "Rising damp analysis and selection of optimal handling method in masonry construction," Periodica Polytechnica: Civil Engineering, vol. 58, no. 4, pp. 431-444, 2014.

[46] P. Michálek, V. Tydlitát, M. Jerman, and R. Černý, "Desalination of historical masonry using hydrophilic mineral wool boards," in Computational Methods and Experimental Measurements XIII, pp. 377-385, WIT Press, Southampton, UK, 2007.

[47] B. Lubelli, R. P. J. van Hees, and A. Hacquebord, "Experimental study of the distribution of chemical products against rising damp in substrates with different water saturation degrees," Construction and Building Materials, vol. 40, pp. 891-898, 2013.

[48] A. S. Guimarães, J. M. P. Q. Delgado, and V. P. De Freitas, "Rising damp in building walls: the wall base ventilation system," Heat and Mass Transfer, vol. 48, no. 12, pp. 2079-2085, 2012.

[49] T. Grundl and P. Michalski, "Electroosmotically driven water flow in sediments," Water Research, vol. 30, no. 4, pp. 811-818, 1996.

[50] L. M. Ottosen and I. Rörig-Dalgaard, "Desalination of a brick by application of an electric DC field," Materials and Structures, vol. 42, no. 7, pp. 961-971, 2009.

[51] C. Rodriguez-Navarro and E. Doehne, "Salt weathering: influence of evaporation rate, supersaturation and crystallization pattern," Earth Surface Processes and Landforms, vol. 24, no. 2-3, pp. 191-209, 1999.

[52] Z. Silva and J. da Cruz, "Rock alteration and its relation to surface finishing," Key Engineering Materials, vol. 548, pp. 189196, 2013.

[53] B. J. Smith, M. Gomez-Heras, and S. McCabe, "Understanding the decay of stone-built cultural heritage," Progress in Physical Geography, vol. 32, no. 4, pp. 439-461, 2008.

[54] B. Salvadori, D. Pinna, and S. Porcinai, "Performance evaluation of two protective treatments on salt-laden limestones and marble after natural and artificial weathering," Environmental Science and Pollution Research, vol. 21, no. 3, pp. 1884-1896, 2014.

[55] G. Cappelletti, P. Fermo, and M. Camiloni, "Smart hybrid coatings for natural stones conservation," Progress in Organic Coatings, vol. 78, pp. 511-516, 2015.

[56] L. Pinho, F. Elhaddad, D. S. Facio, and M. J. Mosquera, "A novel $\mathrm{TiO}_{2}-\mathrm{SiO}_{2}$ nanocomposite converts a very friable stone into a self-cleaning building material," Applied Surface Science, vol. 275, pp. 389-396, 2013.

[57] C. O. Folorunso and M. H. Ahmad, "Performance and resistance of paint used as exterior finish in salt laden environment," Structural Survey, vol. 31, no. 3, pp. 214-224, 2013.

[58] T. D. Gonçalves, L. Pel, and J. D. Rodrigues, "Influence of paints on drying and salt distribution processes in porous building materials," Construction and Building Materials, vol. 23, no. 5, pp. 1751-1759, 2009.

[59] P. Maravelaki-Kalaitzaki, "Hydraulic lime mortars with siloxane for waterproofing historic masonry," Cement and Concrete Research, vol. 37, no. 2, pp. 283-290, 2007.

[60] M. Auras, "Poultices and mortars for salt contaminated masonry and stone objects," in Proceedings of the International Conference on Salt Weathering on Buildings and Stone Sculptures, pp. 197-217, Copenhagen, Denmark, 2008.
[61] D. Young and D. Ellsmore, Salt Attack and Rising Damp: A Guide to Salt Damp in Historic and Older Buildings, Heritage Council of NSW, Heritage Victoria, South Australian Department for Environment and Heritage, Adelaide City Council, South Australia, Australia, 2nd edition, 2008.

[62] T. Rivas, E. Alvarez, M. J. Mosquera, L. Alejano, and J. Taboada, "Crystallization modifiers applied in granite desalination: the role of the stone pore structure," Construction and Building Materials, vol. 24, no. 5, pp. 766-776, 2010.

[63] J. Charola, S. Freedland, and S. Centeno, Salts in Ceramic Bodies IV: Considerations on Desalinations, vol. 7 of Restoration of Buildings and Monuments, 2001.

[64] K. Kamran, L. Pel, A. Sawdy, H. Huinink, and K. Kopinga, "Desalination of porous building materials by electrokinetics: an NMR study," Materials and Structures, vol. 45, no. 1-2, pp. 297-308, 2012.

[65] I. Rörig-Dalgaard, "Development of a poultice for electrochemical desalination of porous building materials: desalination effect and pH changes," Materials and Structures, vol. 46, no. 6, pp. 959-970, 2013.

[66] L. M. Ottosen and I. V. Christensen, "Electrokinetic desalination of sandstones for $\mathrm{NaCl}$ removal-test of different clay poultices at the electrodes," Electrochimica Acta, vol. 86, pp.192202, 2012.

[67] I. Rörig-Dalgaard, "Further developments of a poultice for electrochemical desalination of porous building materials: minimization of side effects," Materials and Structures, vol. 48, no. 6, pp. 1901-1917, 2015.

[68] J. M. Paz-García, B. Johannesson, L. M. Ottosen, A. B. Ribeiro, and J. M. Rodríguez-Maroto, "Simulation-based analysis of the differences in the removal rate of chlorides, nitrates and sulfates by electrokinetic desalination treatments," Electrochimica Acta, vol. 89, pp. 436-444, 2013.

[69] A. Sawdy, B. Lubelli, V. Voronina, and L. Pel, "Optimizing the extraction of soluble salts from porous materials by poultices," Studies in Conservation, vol. 55, no. 1, pp. 26-40, 2010.

[70] C. Groot, R. van Hees, and T. Wijffels, "Selection of plasters and renders for salt laden masonry substrates," Construction and Building Materials, vol. 23, no. 5, pp. 1743-1750, 2009.

[71] H. P. Huinink, J. Petkovic, L. Pel, and K. Kopinga, "Water and salt transport in plaster/substrate systems," Heron, vol. 51, no. 1, pp. 9-31, 2006.

[72] J. Petković, H. P. Huinink, L. Pel, K. Kopinga, and R. P. J. Van Hees, "Salt transport in plaster/substrate layers," Materials and Structures/Materiaux et Constructions, vol. 40, no. 5, pp. 475490, 2007.

[73] M. Karoglou, A. Bakolas, A. Moropoulou, and A. Papapostolou, "Effect of coatings on moisture and salt transfer phenomena of plasters," Construction and Building Materials, vol. 48, pp. 3544, 2013.

[74] A. Heritage, F. Sawdy, V. Funke, A. Vergès-Belmin, and A. Bourgès, "How do conservators tackle desalination? An international survey of current poulticing methods," in Proceedings of the 8th European Conference on Research for Protection, Conservation and Enhancement of Cultural Heritage (CHRESP' 08), Ljubljana, Slovenia, 2008.

[75] J. Grave, L. Krage, R. Lusis, and I. Vitina, "Desalination of brick masonry and stone carvings in Capitullum hall of Riga Dome Cathedral," in Proceedings of the 5th Baltic Conference on Silicate Materials, vol. 25 of IOP Conf. Series: Materials Science and Engineering, 2011. 
[76] L. Pel, A. Sawdy, and V. Voronina, "Physical principles and efficiency of salt extraction by poulticing," Journal of Cultural Heritage, vol. 11, no. 1, pp. 59-67, 2010.

[77] V. Verges-Belmin and H. Siedel, "Desalination of masonries and monumental sculptures by poulticing: a review," Restoration of Buildings and Monuments, vol. 11, no. 6, pp. 1-18, 2005.

[78] B. Lubelli and R. P. J. van Hees, "Desalination of masonry structures: fine tuning of pore size distribution of poultices to substrate properties," Journal of Cultural Heritage, vol. 11, no. 1, pp. 10-18, 2010.

[79] V. Voronina, L. Pel, A. Sawdy, and K. Kopinga, “The influence of osmotic pressure on poulticing treatments for cultural heritage objects," Materials and Structures/Materiaux et Constructions, vol. 46, no. 1-2, pp. 221-231, 2013.

[80] A. Bourgès and V. Vergès-Belmin, "Application of fresh mortar tests to poultices used for the desalination of historical masonry," Materials and Structures, vol. 44, no. 7, pp. 1233-1240, 2011.

[81] V. Vergès-Belmin, A. Heritage, and A. Bourgès, "Powdered cellulose poultices in stone and wall painting conservationmyths and realities," Studies in Conservation, vol. 56, no. 4, pp. 281-297, 2011.

[82] T. Lombardo and S. Simon, "Laboratory study on desalination by poultices," in Proceedings of the European Research on Cultural Heritage: State-of-the-Art Studies, 5 ed., ARCCHIP SALTeXPERT Workshop, pp. 275-285, Co-Organized with the Getty Conservation Institute, Los Angeles, Calif, USA, 2006.

[83] V. V.-B. Bourgés, "Comparison and optimization of five desalination systems on the inner walls of Saint Philibert Church in Dijon, France," in Proceedings of the Salt Weathering on Building and Stone Sculptures International Conference (SWBSS '08), Copenhagen, Denmark, 2008.

[84] J. Mertz and P. Loutrel, "Le dessalement des tuffeaux du chateau des duc de bretagne a nantes par la méthode de nettoyage Tollis," Pierre Actual, vol. 779, pp. 68-75, 2001.

[85] I. Antepara, L. Fiala, Z. Pavlík, and R. Černý, "Moisture dependent thermal properties of hydrophilic mineral wool: application of the effective media theory," Medziagotyra, vol. 21, no. 3, pp. 449-454, 2015.

[86] I. Antepara, Z. Pavlík, J. Žumár, M. Pavlíková, and R. Černý, "Properties of hydrophilic mineral wool for desalination of historical masonry," Materials Science, vol. 22, no. 1, pp. 88-93, 2016.

[87] Z. Antepara, M. Pavlík, M. Jerman, R. Pavlíková, and R. Černý, "Characterization of the effect of wetting-drying cycles on the behaviour of hydrophilic additives in mineral wool," WIT Transaction on Engineering Sciences, vol. 90, pp. 71-82, 2015.

[88] A. S. Guimarães, V. P. de Freitas, and J. M. P. Q. Delgado, "Wall base ventilation system to treat rising damp," in Proceedings of the 5th International Building Physics Conference (IBPC '12), Kyoto, Japan, May 2012.

[89] V. P. de Freitas, M. I. Torres, A. Ascenção, and P. F. Gonçalves, "Tratamento da humidade ascensional na Igreja de Vilar de Frades," Revista Património Estudos, pp. 54-62, 2002.

[90] M. I. M. Torres and V. P. de Freitas, "Rising damp in historical buildings Research in Building Physics," in Proceedings of the 2nd International Conference on Building Physics, pp. 369-375, Leuven, Belgica, September 2003.

[91] V. P. de Freitas and A. S. Guimarães, "Characterization of a hygro-regulated wall base ventilation system for treatment of rising damp in historical buildings," in Proceedings of the 2nd
Nordic Symposium on Building Physics, pp. 911-919, Copenhagen, Denmark, 2008.

[92] M. I. M. Torres and V. P. de Freitas, "Wall base ventilation for rising damp control in historical buildings: research and practice "' in Proceedings of the 10th Canadian Conference on Building Science and Technology, pp. 174-183, Ottawa, Canada, 2005.

[93] I. Torres and V. P. D. Freitas, "The influence of the thickness of the walls and their properties on the treatment of rising damp in historic buildings," Construction and Building Materials, vol. 24, no. 8, pp. 1331-1339, 2010.

[94] M. I. M. Torres and V. P. de Freitas, "Treatment of rising damp in historical buildings: wall base ventilation," Building and Environment, vol. 42, no. 1, pp. 424-435, 2007.

[95] A. S. Guimarães, Caracterização experimental do funcionamento de sistemas de ventilação da base das paredes para tratamento da humidade ascensional [M.S. dissertation], Faculdade de Engenharia da Universidade do Porto-FEUP, 2008.

[96] V. P. de Freitas, A. S. Guimarães, and M. I. M. Torres, "The experimental characterization of a wall base ventilation system for the treatment of rising damp in historical buildings," in Proceedings of the 12th Symposium for Building Physics, Dresden, Alemanhã, March 2007.

[97] V. P. de Freitas, I. Sereno, A. Ascensão, P. Gonçalves, A. S. Guimarães, and M. A. Santos, Ventilação da Base das Paredes como Técnica de Tratamento da Humidade Ascensional em Edifícios Históricos-Estudo de Caso, Revista Pedra e Cal, 2007.

[98] V. P. de Freitas, M. I. M. Torres, and A. S. Guimarães, Humidade Ascensional, FEUP, Porto, 2008.

[99] A. S. Guimares and V. P. De Freitas, "Wall base ventilation system as a new technique to treat rising damp in existent buildings," Journal of Building Appraisal, vol. 5, no. 2, pp. 187195, 2009.

[100] A. S. Guimarães, J. M. P. Q. Delgado, and V. P. de Freitas, "Treatment of rising damp in historic buildings," in Heat and Mass Transfer in Porous Media, J. M. P. Q. Delgado, Ed., vol. 13 of Advanced Structured Materials, chapter 1, pp. 1-23, Springer, Berlin, Germany, 2012.

[101] A. S. Guimarães, J. M. P. Q. Delgado, and V. P. de Freitas, "Degradation of walls with rising damp problems: numerical and mathematical analysis of the evaporative process," in Proceedings of the 12th International Conference on Building Materials and Components (XII DBMC '11), vol. 2, pp. 771-778, Porto, Portugal, April 2011.

[102] A. S. Guimarães, J. M. P. Q. Delgado, and V. P. de Freitas, "Rising damp in historic buildings: the wall base ventilation system," in Proceedings of the 9th Nordic Symposium on Building Physics (NSB '11), Tampere, Finland, June 2011.

[103] M. I. M. Torres and V. P. de Freitas, "The influence of the thickness of the walls and their properties on the treatment of rising damp in historic buildings," Construction and Building Materials, vol. 24, no. 8, pp. 1331-1339, 2010.

[104] Schmitt, Maucher-Vorrichtung zum Be und Entlüften insbesondere des Fundaments eines Bauwerks, PatenteDE3902065A1, 1991, http://depatisnet.dpma.de/ipc/cipc.do;jsessionid = 83946531D1BD6E2885C8E6072A395696.dp-app05?s= E02D0003120000\&v $=20100101 \& \mathrm{l}=\mathrm{DE} \& \mathrm{dh}=\mathrm{dh} 11 \& \mathrm{~d}=$ null $\& \mathrm{sn}=$ $\mathrm{n} 00 \& \mathrm{ssw}=$ yes \&sci=i00.

[105] M. P. James, Basement water drainage conduit, Patente US 6598 360 B1, 2003, http://www.google.com/patents/US6598360. 
[106] M. T. Robert, Drying system for structural waterproofing, Patente US 2004/0139688 A1, 2004, http://ip.com/patapp/ US20040139688.

[107] V. P. de Freitas, M. I. M. Torres, and A. S. Guimarães, "Sistema higro-regulável de ventilação da base das paredes para tratamento da humidade ascensional," WO/2010/093272, http:// google.com/patents/WO2010093272A1?cl=ar.

[108] A. S. Guimarães, Wall base ventilation system sizing to rising damp treatment [Ph.D. thesis], Faculty of Engineering, University of Porto-FEUP, 2011. 

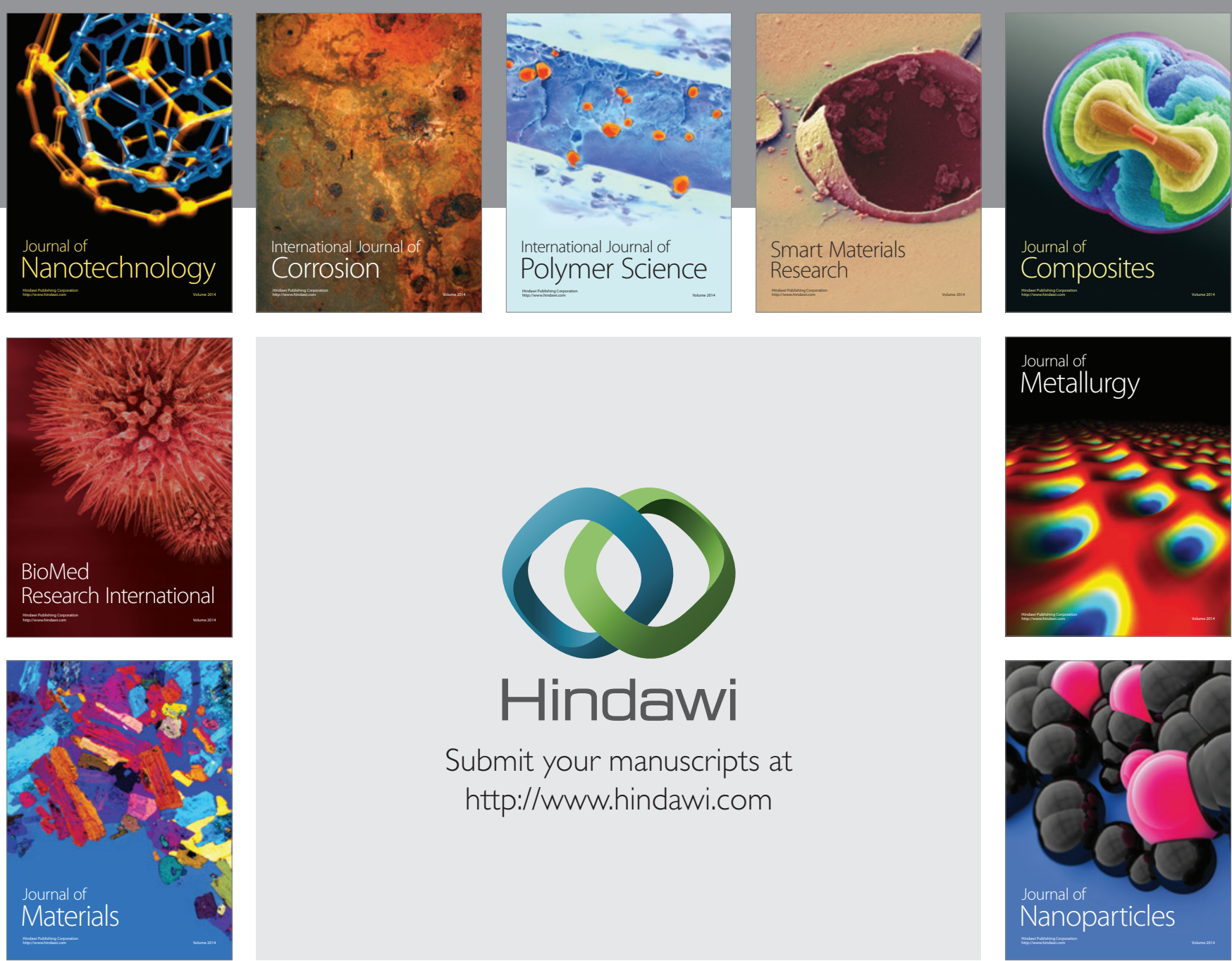

\section{Hindawi}

Submit your manuscripts at

http://www.hindawi.com

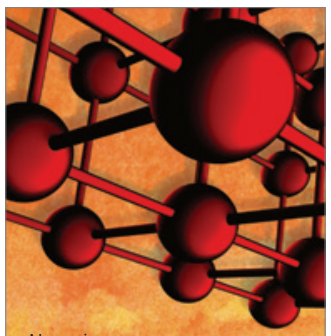

Materials Science and Engineering
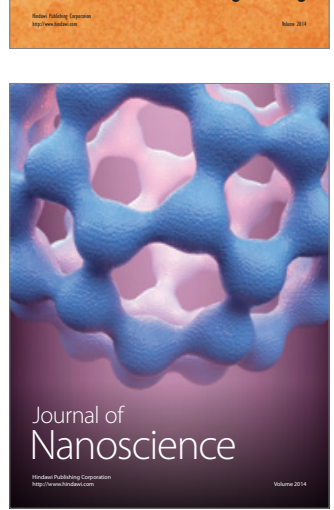
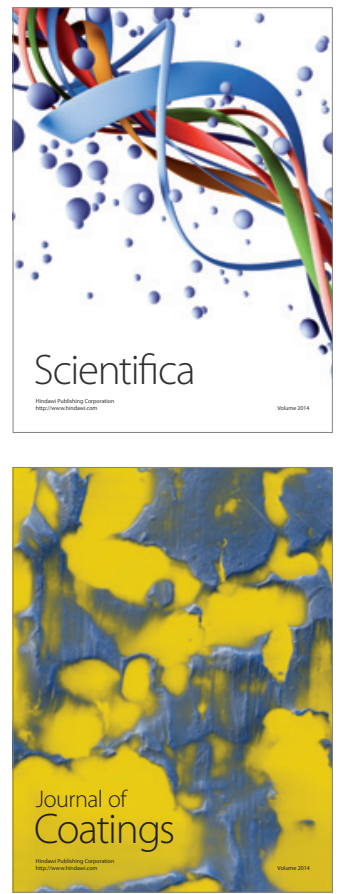
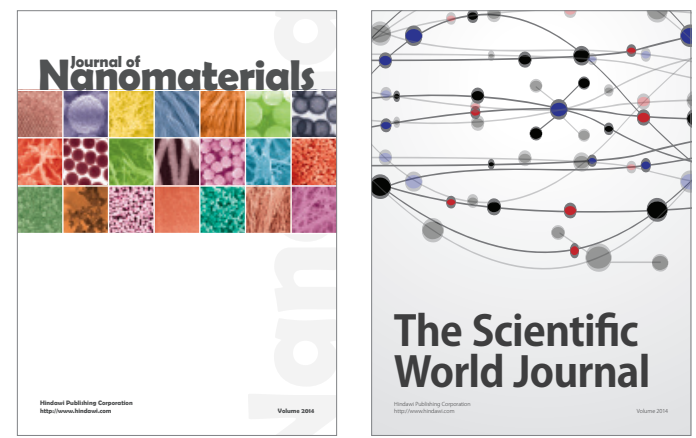

The Scientific World Journal
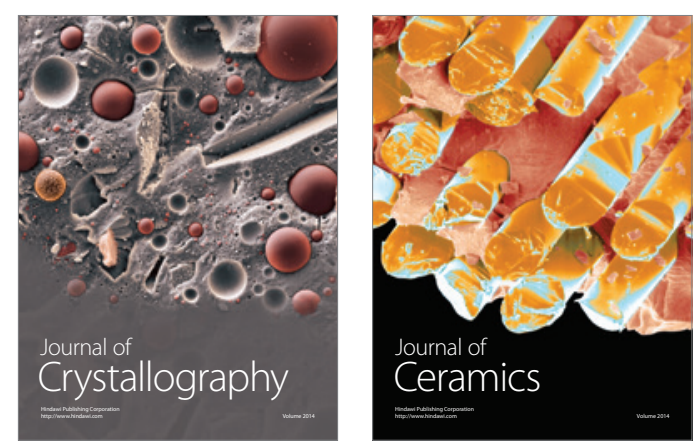
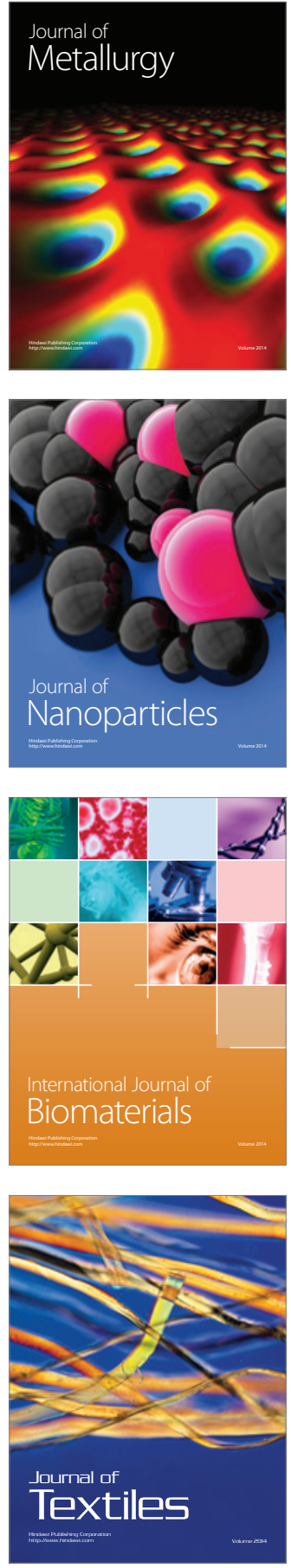